\title{
A Parametric study on the effect of elliptical cutouts for buckling behavior of composite plates under non-uniform edge loads
}

\author{
Subash Chandra K S S,b* $^{\text {iD }, ~ T ~ R a j a n n a c ~(D), ~ K ~ V e n k a t a ~ R a o ~}{ }^{a}$ (D) \\ ${ }^{a}$ Department of Mechanical Engineering, B.M.S College of Engineering, Bengaluru, India. Email: subashks.17pm@bmsce.ac.in, \\ kvrao771@yahoo.com \\ ${ }^{b}$ Department of Mechanical Engineering, Government Polytechnic, Bagepalli, India. \\ ${ }^{c}$ Department of Civil Engineering, B.M.S College of Engineering, Bengaluru, India. E-mail: t.rajanna@gmail.com \\ * Corresponding author
}

https://doi.org/10.1590/1679-78256225

\begin{abstract}
The solution for the buckling problem of composite laminates is usually based on the assumption that the panels are subjected to uniform edge loads without any discontinuity or damage. Nevertheless, in practice, the panels are provided with various sized opening subjected to non-uniform edge loads. Hence in this work, a finite element analysis is carried out to study the buckling behaviour of composite laminates with various sized elliptical openings under nonuniform edge loads. In the FE formulation, the panels are discretised by adopting 9-noded heterosis element and incorporating the effect of shear deformation and rotary inertia. The correctness of the formulation is validated by correlating the results with available literature. The influence of different sized elliptical cutouts on the buckling behaviour is investigated under the compressive and tensile type of non-uniform in-plane edge loads. The effect of various parameters such as cutout size, ply-orientation, ellipse-orientation, boundary condition and panel thickness is included in this work. It is observed from this work that the elliptical vertical cutout has higher buckling resistance as compared to that of the elliptical horizontal cutout.
\end{abstract}

\section{Keywords}

Laminate; elliptical cutout; non-uniform load; tensile buckling; compressive buckling; 9-noded heterosis element.

\section{Graphical Abstract}

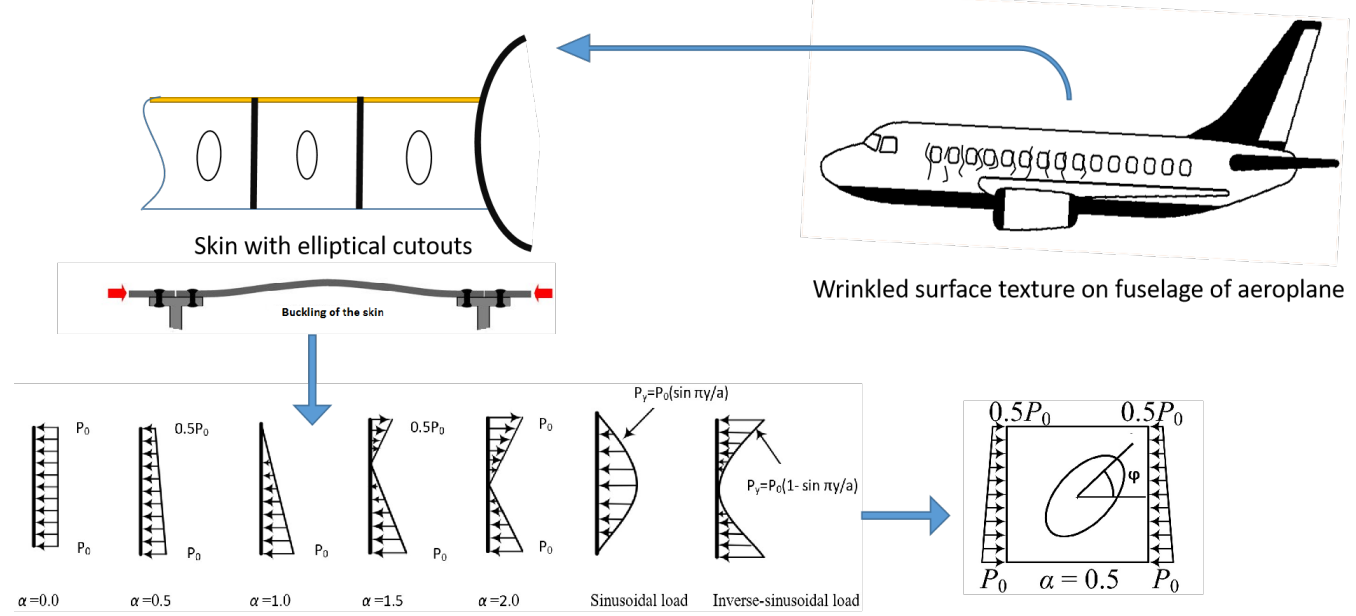

Non-uniform inplane edge load types

Non-uniform load with elliptical cutout orientation 


\section{INTRODUCTION}

A laminated composite comes under the class of thin-walled structure, which are regularly found in several engineering fields, especially in the field of the aerospace industry. The demand for low weight and high strength aerospace structure lead to the development of fibre-reinforced composite structure. While in operation, these structural elements are subjected to various kinds of in-plane loads. A laminated panel under the influence of in-plane load is susceptible to buckle at mere small stress levels. It hence is the topic of concern for researchers for over several years. Several researchers have investigated the buckling behaviour of laminated panels responding to uniform edge loads (Reddy and Phan, 1985; Khedmati and Edalat, 2010; Mirzaei et al., 2015; Sayyad and Ghugal, 2014; Sayyad et al., 2016; Singh and Chakrabarti, 2012; Bourada et al., 2019).

Nevertheless, in several realistic stability problem, the enforced edge load is non-uniform in nature (Lal and Saini, 2013; Tang and Wang, 2011; Zhong and Gu, 2007). Rajanna et al. (2016a) studied the effect of partial load on the composite stiffened plate. In such an instance, the stress distributions are likewise non-uniform. The solutions to such problems are quite complicated. The difficulty in solving the buckling problem is further enhanced by inducing cutout within the panel. The panels with cutouts are commonly found in aerospace and ship structure to facilitate inspection for fuel/water lines and sometimes to lessen the overall weight of the structure. The introduction of cutout within a panel reduces overall strength resulting in premature failure due to buckling. Hence, a sound consciousness of buckling characteristic is necessary to design the laminated panel with cutout during the act of non-uniform edge loads. Jain and Kumar (2004); Ghannadpour et al. (2006); Baba and Baltaci (2007); Kumar and Singh (2010) explored the buckling analysis of composite laminate plates with a central circular cutout under uniformly distributed uniaxial edge compression. Aydin Komur et al. (2010) considered the elliptical cutout for analyzing buckling behaviour with woven glass polyester material.

Lately, the optimal position for maximum buckling load with the circular cutout in the orthotropic plate is investigated for uniaxial compressive load by Choudhary and Jana (2018). Muc et al. (2018b) described the stability loss in composite structure focusing on buckling and post-buckling behaviour with cutout and reinforcement. Narayana et al. (2014); Rajanna et al. (2017, 2018); Abolghasemi et al. (2019) studied the effect of linearly varying edge loads on the stability of composite plates with a circular or square cutout. Aydin Komur et al. (2008) and Chandra et al. (2020a, 2020b, 2021) analysed the buckling behaviour of composite laminate under non-uniform varying in-plane compressive loads with circular cutouts.

The buckling analysis of the panel considered so far is under the action of compressive edge loads. But, in some cases, panels are also subjected to the tensile type of non-uniform edge loads. Leissa and Ayoub (1988); Deolasi et al. (1995); Rajanna et al. (2016a) analysed the effects of uniaxial tensile concentrated/patch loads on isotropic/composite plates. The tension buckling phenomenon is practically more importance, especially for the panel with defects like cracks or cutouts. The existence of compressive stresses and stress concentrations in the anisotropic tensile plate with cutouts, is demonstrated by Savin (1962). Shimizu (2007) and Rajanna et al. (2016b) investigated tensile buckling characteristic of the panel with centrally placed square and circular cutout.

The elliptic configuration is used for window openings in aircraft fuselages. It is recommended for maintenance holes by the ASME Code for Unfired Pressure Vessels and the British Standard Specification (BS 1500) for Fusion Welded Pressure Vessels. The application of these elliptical cutouts within thin-walled structures for aeronautical applications cannot be avoided, as these cutouts being necessary for the realization of doors and windows or the presence of electrical cables and pipes in ship structures. The significance of stress concentration effect on buckling modes in tensioned laminate with circular and elliptical openings is analysed by Muc (2018). Muc and Romanowicz (2017), Muc et al. (2017, 2018a) investigated circular and elliptical (vertical and horizontal) holes in composite laminates for static and fatigue damage. The plate considered in his study is subjected to tensile loading and obtained results from FE and analytical methods and validated with those from the experimental method.

It is revealed from the literature that plenty of efforts are made related to buckling of laminated plates with/without circular and/or square cutouts subjected to uniform edge loads. A very few literature covered the effect of circular and/or square cutouts subjected to compression and/or tension-type of non-uniform edge loads. Further, the effect of the elliptical cutout is also very rare in the literature, which is restricted to uniform edge loads. However, the effect of differently oriented elliptical cutouts under various kinds of non-uniform edge loads is not reported in the literature. Hence, a comprehensive study on the compression and tension buckling behaviour of composite laminates with different sized and oriented elliptical cutout under the consequence of various kinds of non-uniform edge loads is very much essential.

A powerful and flexible FE code has been developed using MATLAB to analyse the panel with elliptical cutouts under nonuniform edge loads. Further, a parametric study is carried out to investigate the effect of cutout size, ply-orientation, orientation of elliptical cutout, boundary condition and panel thickness under non-uniform compressive and tensile edge loads. 


\section{THEORY AND FE FORMULATION}

The geometry of a composite laminated panel with a centrally placed elliptical cutout composing of major diameter ' $\mathrm{d} 1$ ' and minor diameter ' $\mathrm{d} 2$ ', is as shown in Figure $1(\mathrm{a})$. In a laminate, each lamina has different ply orientations whose fibres are oriented at an angle ' $\theta$ ' and meshing pattern of the full panel with a vertical elliptical cutout is shown in Figure $1(\mathrm{~b})$ and 1 (c) respectively.

The different loading patterns considered in this analysis are shown in Figure 2. Figure 2(a) to 2(e) represents different linearly varying loads ' $P_{y}$ ' obtained by changing the values of loading factors ' $\alpha$ ' in the Equation (1), in which ' $P_{0}$ ' is the loading intensity. For instance, $\alpha=0$ define uniformly distributed load and $\alpha=2$ define pure in-plane bending.

$P_{y}=P_{o}\left(1-\alpha \frac{y}{b}\right)$

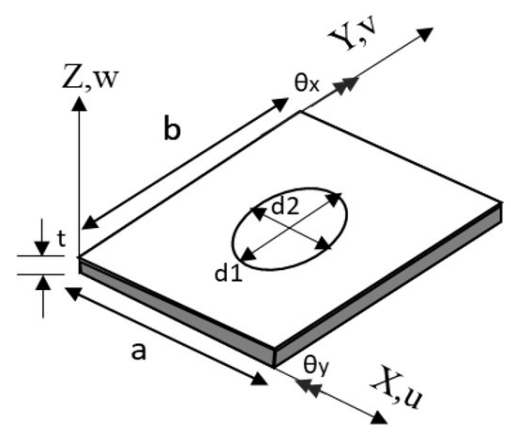

(a)

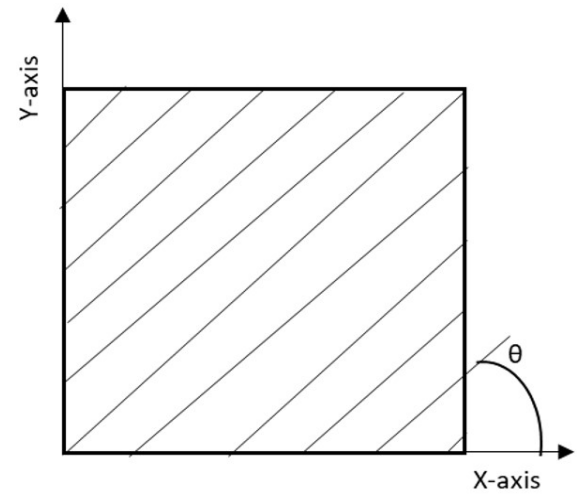

(b)

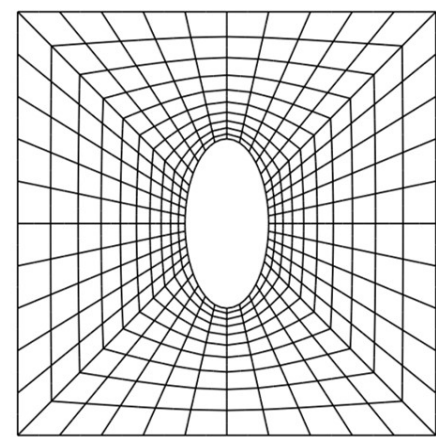

(c)

Figure 1 (a) Geometry of the laminate (b) Ply-orientation in a distinct lamina (c) Meshing pattern with an elliptical vertical cutout

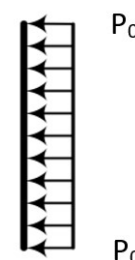

$\alpha=0.0$

(a)

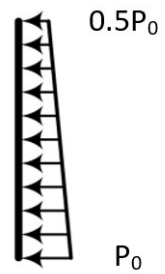

$\alpha=0.5$

(b)

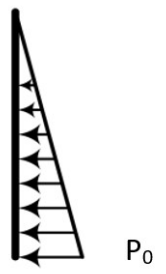

$\alpha=1.0$

(c)

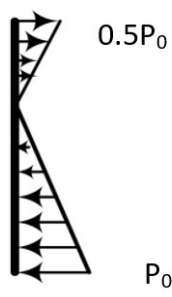

$\alpha=1.5$

(d)

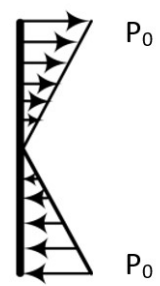

$\alpha=2.0$

(e)

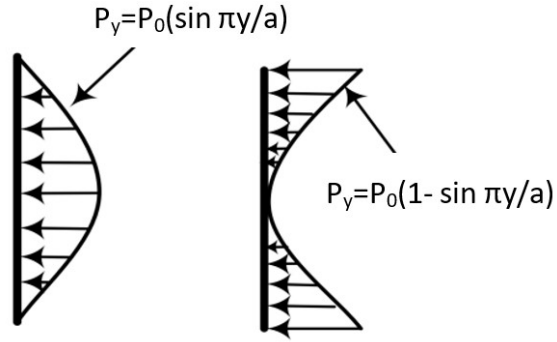

Sinusoidal load

(f)
Inverse-sinusoidal load

(g)

Figure 2 Patterns of non-uniform edge loads

\subsection{Strain-displacement relations}

The current study is limited to Reissner-Mindlin hypothesis, which incorporates the effect of shear deformation in the formulation. According to this hypothesis, the mid-surface normal remains straight but not necessarily remain perpendicular to the mid-plane after bending.

The displacement field at any distance from the plate mid-plane can be expressed as

$$
\begin{aligned}
& u(x, y, z)=u_{0}(x, y)+z \theta_{x}(x, y) \\
& v(x, y, z)=v_{0}(x, y)+z \theta_{y}(x, y) \\
& w(x, y, z)=w_{0}(x, y)
\end{aligned}
$$


where $u, v$ and $w$ define the displacement of any arbitrary point $(x, y, z)$ in the laminate space; $u_{0}, v_{0}$ are the in-plane displacements and $w_{0}$ is the transverse displacement of a point $(x, y)$ on the middle plane; $z$ is the distance of any layer from the middle plane of the plate; $\vartheta_{x}$ and $\vartheta_{y}$ are rotations of transverse normal along $y$ - and $x$-axes respectively.

Equation (3) gives the corresponding strain

$$
\{\varepsilon\}=\left\{\varepsilon_{l}\right\}+\left\{\varepsilon_{n l}\right\}
$$

where, $\left\{\varepsilon_{l}\right\}$ is the linear strain terms for deriving the elastic stiffness matrix and $\left\{\varepsilon_{n l}\right\}$ is the non-linear strain that is used to derive the geometric stiffness matrix (Bathe, 1996).

In conformity with the assumptions that the normal stress may be assumed small and negligible, and the corresponding strain equals to zero. The stress-strain relation of any $k^{\text {th }}$ lamina based on displacement model is given

$$
\{\sigma\}=\left(\bar{Q}_{i j}\right)_{k}\left\{\varepsilon_{l}\right\}
$$

Upon integrating through the laminate thickness, the Equation (4) is reduced to

$\left\{N^{p}\right\}=\left[C^{p}\right]\left\{\varepsilon^{p}\right\}$

where, $\left\{N^{P}\right\}=\left[\left\{N_{i}^{P}\right\}, \quad\left\{M_{i}^{P}\right\}, \quad\left\{Q_{i}^{P}\right\}\right]^{T}$ and $\left\{\varepsilon^{P}\right\}=\left[\begin{array}{ccc}\varepsilon_{j}^{P} & \chi_{j}^{P} & \gamma_{j}^{P}\end{array}\right]^{T}$ are corresponding stress resultants and strains, respectively. $\left[C^{p}\right]$ is the constitutive matrix of the laminate and is given in Equation (6),

$$
\left[C^{P}\right]=\left[\begin{array}{ccc}
{\left[A_{i j}^{p}\right]} & {\left[B_{i j}^{P}\right]} & 0 \\
{\left[B_{i j}^{P}\right]} & {\left[D_{i j}^{P}\right]} & 0 \\
0 & 0 & {\left[S_{i j}^{P}\right.}
\end{array}\right]
$$

in which, the extension-extension $\left[A_{i j}^{p}\right]$, extension-bending $\left[B_{i j}^{P}\right]$, bending-bending $\left[D_{i j}^{P}\right]$ of the stiffness components expressed as

$$
\left(A_{i j}^{p}, \quad B_{i j}^{P}, \quad D_{i j}^{P}\right)=\sum_{k=1}^{n} \int_{z_{k-1}}^{z_{k}}\left(\overline{Q_{i j}}\right)_{k}\left(1, \quad z, \quad z^{2}\right) d z, \quad i, j=1,2,6
$$

and

$$
S_{i j}^{P}=\sum_{k=1}^{n} \int_{z_{k-1}}^{z_{k}} \alpha\left(\overline{Q_{i j}}\right) d z, \quad i, j=4,5
$$

where, ' $n$ ' is the number of ply-layers; $\alpha=5 / 6$ is a shear-correction factor (Reddy, 1996); $\left(\overline{Q_{i j}}\right)_{k}$ is the stiffness matrix of the $k^{\text {th }}$ lamina regarding plate axes.

\subsection{Finite element formulation}

In the present work, the plate is discretised employing a nine-node (9-N) Heterosis element, which is a combination of eight-node (8-N) Serendipity and nine-node (9-N) Lagrange elements. This element under the present study has 5 degrees of freedom $\left(u, v, w, \vartheta_{x}\right.$ and $\left.\vartheta_{y}\right)$ at all edge nodes of an element and 4 degrees of freedom $\left(u, v, \vartheta_{x}\right.$ and $\left.\vartheta_{y}\right)$ at the inner nodes as shown in Figure 3 (Hughes and Cohen, 1978; Butalia et al., 1990). 


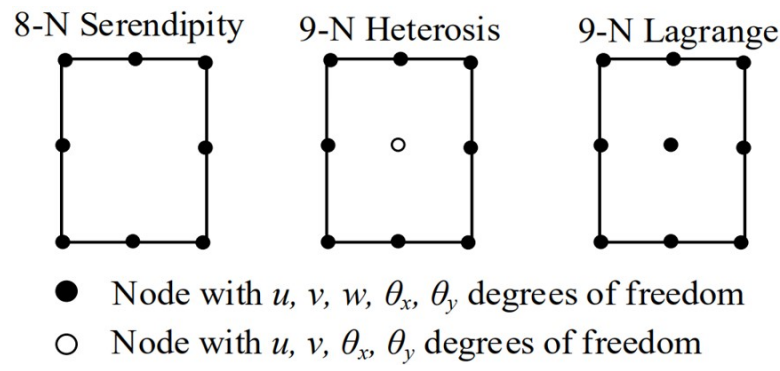

Figure 3 Different types of plate elements

The different participating element-level matrices such as elastic stiffness matrix [ $k$, geometric stiffness matrix [ $\left.k_{g}\right]$ and consistent mass matrix $[m]$ have been derived using corresponding energy expressions (Bathe, 1996)

$[k]=\int_{-1}^{+1} \int_{-1}^{+1}[B]^{T}[C][B]|J| d \xi d \eta$

$\left[k_{g}\right]=\int_{-1}^{+1} \int_{-1}^{+1}\left[B_{G}\right]^{T}[S]\left[B_{G}\right]|J| d \xi d \eta$

$[m]=\int_{-1}^{+1} \int_{-1}^{+1}[\bar{N}]^{T}[I][\bar{N}]|J| d \xi d \eta$

in which, $[B]$ is elemental strain displacement matrix; $[C]$ is the constitutive matrix; $\left[B_{G}\right]$ is elemental non-linear strain displacement matrix; $[S]$ is initial pre-buckling stress matrix; $|J|$ is the Jacobian determinant; $[\bar{N}]$ is the shape function matrix; $[I]$ is the inertia matrix consisting of $I_{1}, I_{2}$ and $I_{3}$ which are given by $\left(I_{1}, I_{2}, I_{3}\right)=\sum_{k=1}^{L} \int_{z_{k-1}}^{z_{k}} \rho_{k}\left(1, z, z^{2}\right) d z$. The different participating matrices from Equations (9), (10) and (11) are not shown here to avoid repetitions, which are referred from Rajanna et al. (2016a).

\subsection{Governing Equation}

The generalized governing equilibrium equation for vibration and buckling problem can be written as

$[M]\{\ddot{q}\}+\left[[K] \pm P\left[K_{g}\right]\right]\{q\}=\{0\}$

where, $[K],\left[K_{g}\right]$ and $[M]$ represents assembled system stiffness, geometric stiffness and consistent mass matrices respectively and represent the eigenvector for different modes of buckling. Since the applied load is non-uniform in nature, the buckling loads are calculated by the dynamic approach by solving the Equation (12). In this approach, the natural frequency reduces with the increase in the intensity of in-plane load $P$ and finally becomes zero at the onset of buckling. The load at which the frequency becomes zero is called buckling load.

Computer code is developed using MATLAB to perform all the necessary computations. In the code, a selective integration scheme is incorporated for the generation of element elastic stiffness matrix. The $3 \times 3$ Gauss quadrature rule is adopted for membrane as well as bending terms and $2 \times 2$ Gauss rule for shear terms to avoid possible shear locking. The geometric stiffness matrix is primarily a function of the in-plane stress distribution in an element due to applied edge loads. Since the stress field is non-uniform for a given boundary and loading conditions, the plane stress analysis is carried out using a standard FE procedure to determine the stresses at $3 \times 3$ Gauss sampling points. Accordingly, the integration for the generation of the geometric stiffness matrix is done using $3 \times 3$ Gauss quadrature rule.

\section{RESULTS AND DISCUSSIONS}

The problem considered here consists of a thin square laminated panels of thickness $(t)$ to width $(b)$ ratio $=0.01$, elliptical cutout ratio (major axis diameter (d1) to width of plate $(b)$ ) varied from $\mathrm{d} 1 / \mathrm{b}=0.0$ to 0.8 and having material properties, $E_{11} / E_{22}=25, G_{12} / E_{22}=G_{13} / E_{22}=0.50, G_{23} / E_{22}=0.20$ and $v_{12}=0.25$ unless otherwise stated. To define the 
boundary conditions, the notations, $S$ (simply supported) and $C$ (clamped) are used in the string of various boundary conditions. In the analysis, the buckling results are calculated in two different stages. Firstly, the pre-buckling analysis is carried out in order to determine the in-plane stress distributions within the plate element. The critical buckling loads are then calculated using the in-plane stresses.

The displacement boundary conditions considered for both pre-buckling and buckling analyses are as follows:

Simply supported boundary condition (SSSS)

- $\quad$ For pre-buckling stress analysis: $w=\vartheta_{y}=0$ at $x=0, b ; w=\vartheta_{x}=0$ at $y=0, a$ and $u=0, v=0$ at two nodes along the edges $x=b / 2$ and $y=a / 2$ respectively.

- $\quad$ For buckling analysis: $u=w=\vartheta_{y}=0$ along $x=0, b ; v=w=\vartheta_{x}=0$ along $y=0, a$.

Clamped boundary condition (CCCC)

- $\quad$ For pre-buckling stress analysis: $w=\vartheta_{y}=\vartheta_{x}=0$ along $x=0, b$ and $y=0, a$ and $u=0, v=0$ at two nodes along the edges $x=b / 2$ and $y=a / 2$ respectively.

- $\quad$ For buckling analysis: $u=v=w=\vartheta_{x}=\vartheta_{y}=0$ along $x=0, b$ and $y=0, a$.

The critical loads are presented in the non-Dimensional form as follows (Reddy and Phan 1985; Zhong and Gu 2007):

Non-dimensional load, $\gamma_{c r}=\frac{P_{c r} a^{2}}{E_{22} t^{3}}$

where, $P_{c r}$ is the absolute critical load and $t$ is the total thickness of laminate.

\subsection{Comparison with previous work - with and without circular cutout}

To assess the accuracy and effectiveness of different matrices involved in the buckling problem of present investigation, it is required to evaluate the present results along with previous studies. The non-dimensional parameters of a square panel without cutout subjected to various non-uniform loads have been studied and the results are tabulated in Table 1, along with the results of Zhong and Gu (2007). Further, the same study is continued for a panel with a different sized circular cutout subjected to uniform edge load and the obtained results are tabulated in Table 2 along with the results of previous studies. The good agreement is observed between the present study and those from the literature.

Table 1 Comparison of buckling parameter for a cross-ply square panel (0/90/0) under linearly varying loads; $E_{11} / E_{22}=40, G_{12}$ $=\mathrm{G}_{13}=0.6 \mathrm{E}_{22}, \mathrm{G}_{23}=0.5 \mathrm{E}_{22}$ and $\mathrm{u}=0.275$

\begin{tabular}{ccc}
\hline Loading patterns $(\alpha)$ & CFS(Zhong and Gu 2007) & Present \\
\hline 0.5 & 47.267 & 47.256 \\
1.0 & 64.982 & 64.960 \\
1.5 & 91.374 & 91.331 \\
2.0 & 129.785 & 129.727 \\
\hline
\end{tabular}

Table 2 Comparison of buckling load for a SSSS edged square panel with a circular cutout under uniform load; $\mathrm{E}_{11}=130.0 \mathrm{GPa}$, $\mathrm{E}_{22}=10.0 \mathrm{GPa}, \mathrm{G}_{12}=\mathrm{G}_{13}=5.0 \mathrm{GPa}, \mathrm{G}_{23} 5=3.4 \mathrm{GPa}$, and $\mathrm{v}_{12}=0.35$

\begin{tabular}{cccc}
\hline \multirow{2}{*}{$\mathrm{d} / \mathrm{b}$ Ratio } & \multicolumn{3}{c}{$\mathbf{8}$ layers $(\mathbf{0} / \mathbf{9 0})_{2 \mathrm{~s}, \mathrm{~b} / \mathrm{h}=\mathbf{1 0 0}}$} \\
\cline { 2 - 4 } & Present & Rajanna et al. (2016b) & Ghannadpour et al. (2006) \\
\hline 0.0 & 13.82 & 13.82 & 13.79 \\
0.1 & 12.82 & 12.83 & 12.80 \\
0.2 & 10.83 & 10.84 & 10.82 \\
0.3 & 6.41 & 6.4 & 6.4 \\
\hline
\end{tabular}




\subsection{Comparison study- panel with an elliptical cutout}

The comparative study is further continued for the panel with different sized elliptical cutouts under uniformly distributed edge load. The effect of 40-layered (45/-45/0/90) 5 s laminated panel having elliptical-vertical and ellipticalhorizontal cutouts are studied and the results are tabulated in Table 3 along with the results of Jain and Kumar (2004). The excellent agreement has been found between the literature and present studies.

Table 3 Comparison of buckling loads for a SSSS edged square laminated panel with elliptical cutout under uniform edge load;

$$
\mathrm{E}_{11}=130.0 \mathrm{GPa}, \mathrm{E}_{22}=10.0 \mathrm{GPa}, \mathrm{G}_{12}=\mathrm{G}_{13}=5.0 \mathrm{GPa}, \mathrm{G}_{23}=3.4 \mathrm{GPa} \text {, and } \mathrm{v}_{12}=0.35
$$

\begin{tabular}{|c|c|c|c|c|}
\hline \multirow[t]{3}{*}{ d1/b } & \multicolumn{2}{|c|}{ Vertical elliptical cutout } & \multicolumn{2}{|c|}{ Horizontal elliptical cutout } \\
\hline & \multicolumn{2}{|c|}{40 layers $(45 /-45 / 0 / 90)_{5 s}, b / h=75$} & \multicolumn{2}{|c|}{40 layers $(45 /-45 / 0 / 90)_{5 s}, b / h=75$} \\
\hline & Present & Jain and Kumar (2004) & Present & Jain and Kumar (2004) \\
\hline 0.5 & 13.96 & 13.84 & 13.96 & 13.84 \\
\hline 0.4 & 16.09 & 15.95 & 12.95 & 12.83 \\
\hline 0.3 & 18.23 & 18.10 & 13.20 & 13.04 \\
\hline 0.2 & 20.61 & 20.46 & 13.33 & 13.16 \\
\hline
\end{tabular}

\subsection{Buckling results of laminated panels with elliptical cutouts under the action of non-uniform compressive and tensile edge loads}

In this section, the buckling behaviour of four-layered symmetric laminated panel with cross-ply $(0 / 90) s$ and angleply ( \pm 45$)$ s scheme is examined. The loading types considered in this study shown in Figure 4 are non-uniform compressive loads and the corresponding tensile loads are obtained by reversing the direction of loads. The elliptical cutout shown in Figure 4 is horizontally placed, in which ' $\mathrm{d} 1$ ' and ' $\mathrm{d} 2$ ' represents major and minor axis diameter irrespective of orientation of elliptical cutout. Various parametric studies are carried out and discussed in detail in the subsections.

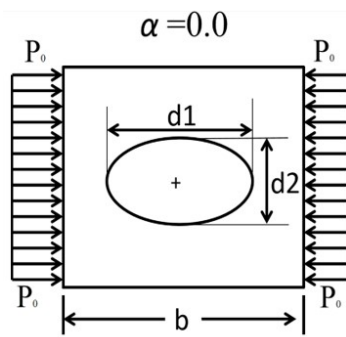

(a)

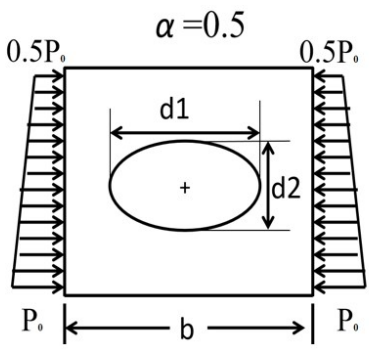

(b)

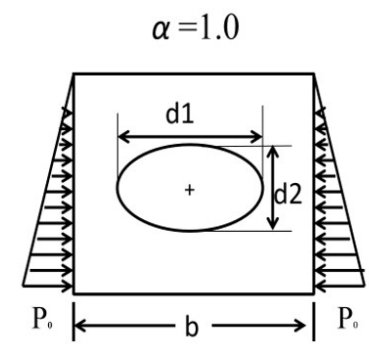

(c)

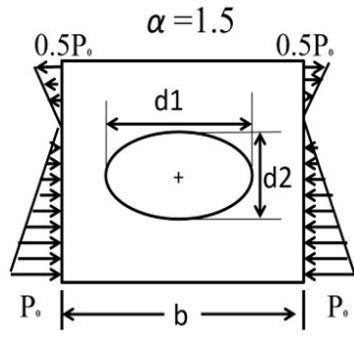

(d)

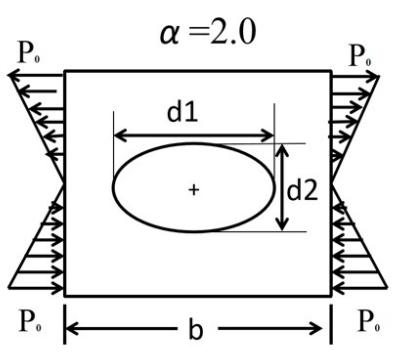

(e)

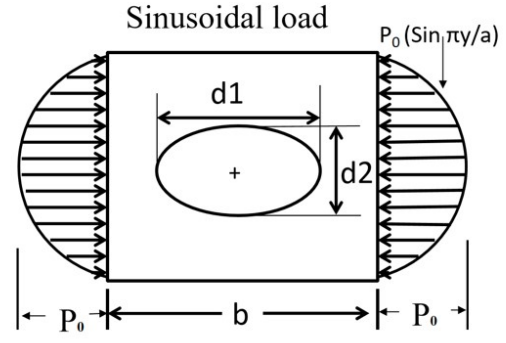

(f)
Inverse sinusoidal load

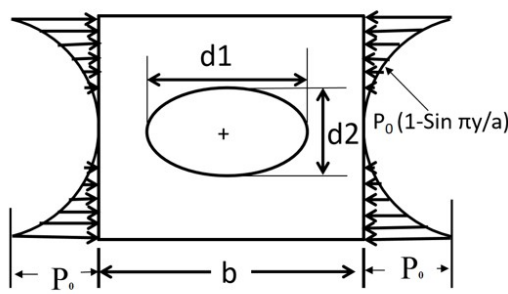

(g)

Figure 4 Square panels with a horizontal elliptical cutout under different non-uniform edge loads

\subsubsection{Cross-ply panel with elliptical cutouts under non-uniform compressive edge loads}

The effect of different elliptical cutout sizes (d1/b) and non-uniform edge loads on symmetrical laminated cross-ply $(0 / 90) s$ panel is analysed for buckling behaviour. The different elliptical cutout sizes placed horizontally and vertically is studied and the results are illustrated in Figure 5(a) and 5(b), respectively. 

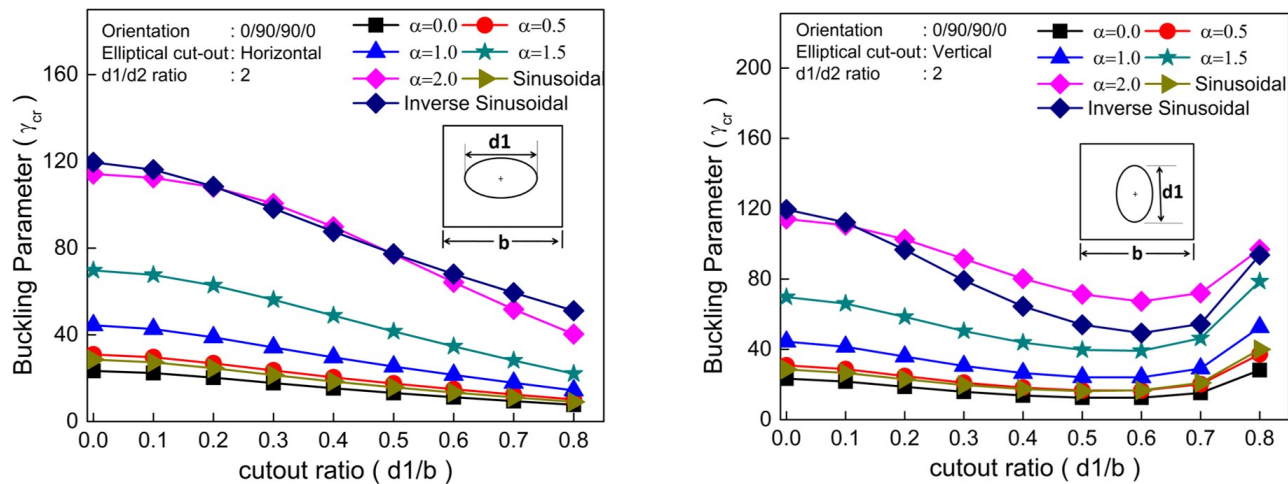

Figure 5 Variation of buckling parameter with different sized elliptical cutouts under non-uniform loads

It is noticed from Figure 5(a) that the buckling parameter $\left(\nu_{\mathrm{cr}}\right)$ reduces with the increase in elliptical cutout size $(\mathrm{d} 1 / \mathrm{b})$ irrespective of loading patterns and buckling resistance is found to be least at $\mathrm{d} 1 / \mathrm{b}=0.8$ and significantly higher at $d 1 / b=0.0$. However, the different behavior is observed when the elliptical cutout is placed vertically, wherein the buckling parameter decreases up to $\mathrm{d} 1 / \mathrm{b}=0.6$ and thereafter increases with the further increase in $\mathrm{d} 1 / \mathrm{b}$. Least buckling resistance is found at $d 1 / b=0.6$ and highest resistance at $d 1 / b=0.0$ and 0.8 , as can be seen in Figure $5(b)$. The increase in buckling resistance beyond $\mathrm{d} 1 / \mathrm{b}=0.6$ is also explained by plotting von-Misses stress distribution around the cutout from $\mathrm{d} 1 / \mathrm{b}=0.4$ to 0.8 , are shown in Figure 6 for a particular case of the inverse-sinusoidal load. It is noticed from Figure 6 that the stress region decreases with the increase in cutout size and found to be significantly lesser at higher sized cutout as compared to that of the smaller sized cutout. This may be the reason for increasing buckling resistance beyond $\mathrm{d} 1 / \mathrm{b}=0.6$. However, this is not true in the case of stress distribution around the horizontal elliptical cutout, wherein the stress region around the cutout increases with the increase in cutout size, which can be seen in Figure 7 . Therefore, this may be the reason for decreasing buckling resistance with the cutout size in the case of horizontal elliptical cutout. It is also noticed in both cases that the buckling parameter found to be significantly higher for $\alpha=2.0$ (pure bending) and inverse-sinusoidal load. This result may be due to the generation of an equal amount of tensile and compressive stresses within the panel in the case of pure bending. The introduction of tensile stresses stabilizes the panel, thereby increasing the buckling resistance significantly as compared to all other loading conditions. In the case of inverse-sinusoidal load, most of the stresses concentrate towards the edges of the panel wherein the stiffness of the panel is significantly higher.

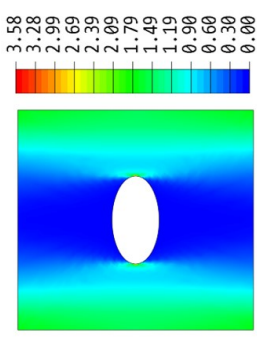

(a)

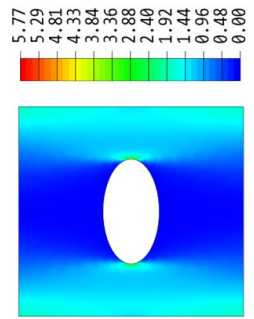

(b)

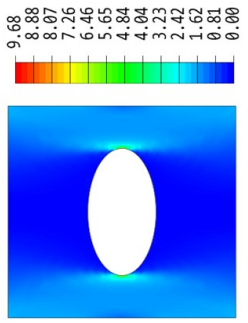

(c)

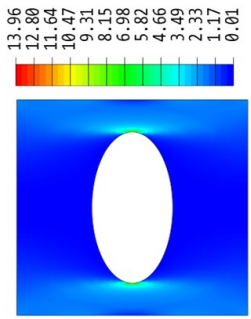

(d)

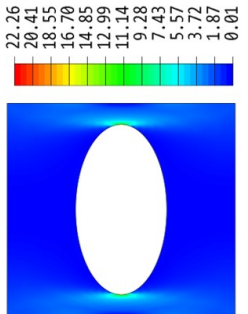

(e)

Figure 6 Stress distribution over cross-ply panel with $d 1 / b=80.4$ to 80.8 under inverse-sinusoidal edge load

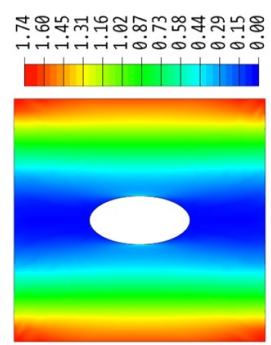

(a)

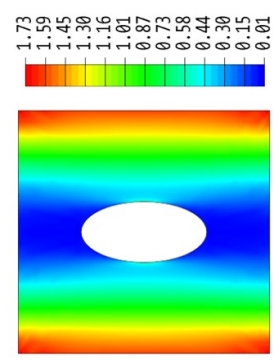

(b)

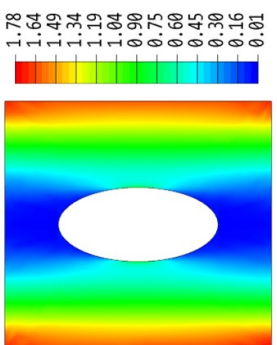

(c)

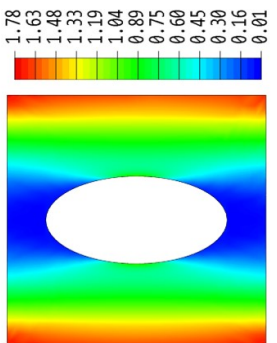

(d)

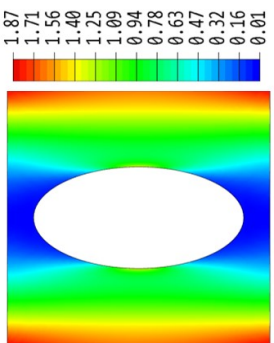

(e)

Figure 7 Stress distribution over cross-ply panel with $\mathrm{d} 1 / \mathrm{b}=0.4$ to 0.8 under inverse-sinusoidal edge load 


\subsubsection{Angle-ply panel with elliptical cutouts under non-uniform compressive edge loads}

The effect of horizontal and vertical elliptical cutouts on the buckling behavior of angle-ply laminated panels with $( \pm 45)_{s}$ layup scheme has been investigated for different loading conditions and the results are illustrated in Figure $8(\mathrm{a})$ and $8(\mathrm{~b})$ respectively. It is noticed from Figure 8(a) that the buckling behavior of angle-ply laminated panel with the horizontal cutout is similar to that of the cross-ply laminated panel with higher buckling parameter in all loading conditions, except for inversesinusoidal load. In this load case, the buckling parameter increases beyond $\mathrm{d} 1 / \mathrm{b}=0.3$. The inference behind this behavior is illustrated by plotting stress distribution around the horizontal elliptical cutout for $\mathrm{d} 1 / \mathrm{b}=0.4$ to 0.8 , as shown in Figure 9 . It is noticed in Figure 9, the intensity of stress within the vicinity of cutout decreases and also shift towards the edges of the panel as cutout size increases. Therefore, this may be the reason for the increase in the buckling parameter beyond $\mathrm{d} 1 / \mathrm{b}=0.3$ for a particular inverse-sinusoidal load case. On the other hand, the buckling parameter found to be increased for all loading cases beyond $\mathrm{d} 1 / \mathrm{b}=0.6$ in the case of the vertical elliptical cutout, which can be seen in Figure $8(b)$. This behavior is similar to that of cross-ply vertical elliptical cutout panel with higher in the values of buckling parameter.

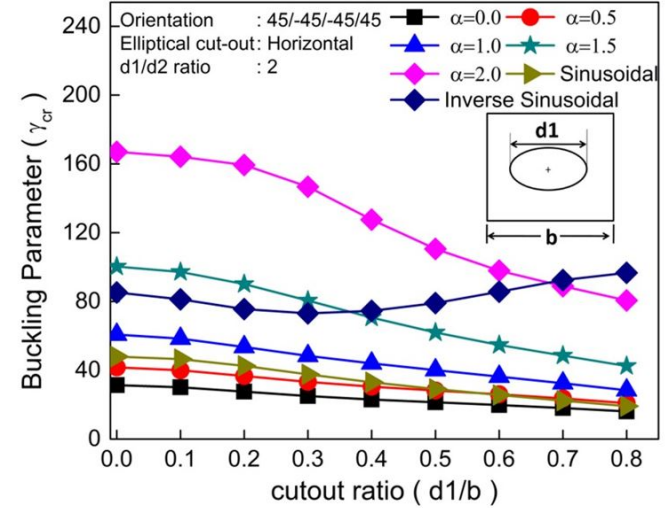

(a) Buckling parameter of angle-ply panel with horizontal elliptical cutout

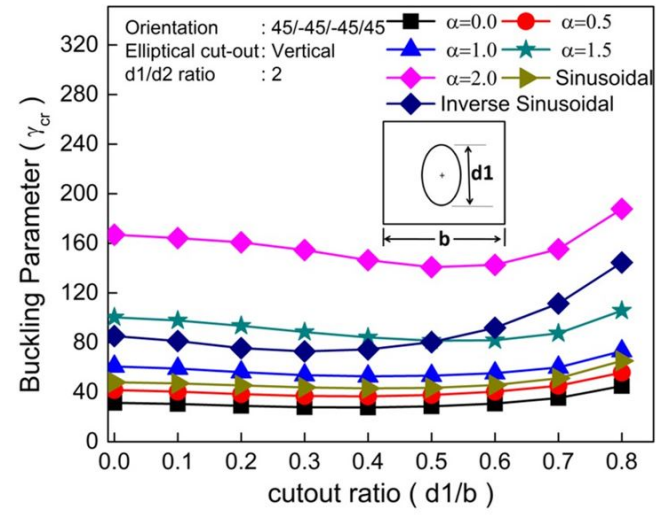

(b) Buckling parameter of angle-ply panel with vertical elliptical cutout

Figure 8 Variation of Buckling parameter with different sized elliptical cutouts under non-uniform loads

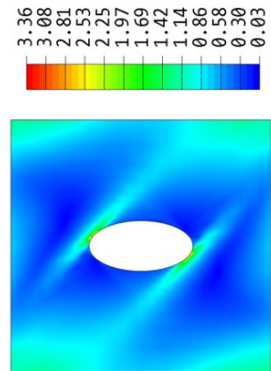

(a)

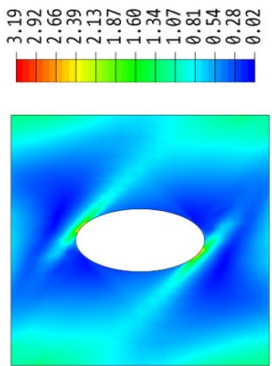

(b)

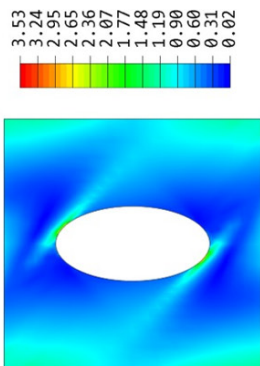

(c)

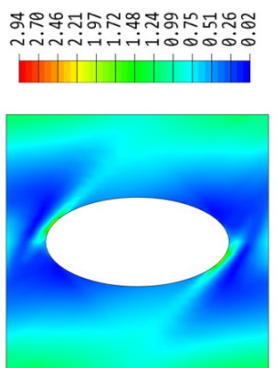

(d)

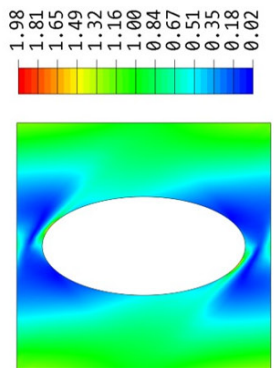

(e)

Figure 9 Stress distribution over angle-ply panel with $d 1 / b=0.4$ to 0.8 under inverse-sinusoidal edge load

\subsubsection{Effect of elliptical cutouts on different ply-orientations}

The effect of horizontal and vertical elliptical cutouts on different layup schemes has been studied for different nonuniform edge loads and the results are shown in Figure 10(a) and 10(b) respectively. The cutout size d1/b is considered as 0.6 and the ratio of elliptical major to minor axis is restricted to 2. It is observed from Figure 10(a) that the buckling parameter gradually increases with the increased ply-orientation till it reaches a maximum ply-angle at around $( \pm 45)_{s}$ irrespective of loading conditions except for inverse-sinusoidal load, wherein the buckling parameter found to be higher at an angle of $( \pm 30)_{s}$. In the case of the vertically placed elliptical cutout as observed in Figure $10(b)$, the buckling parameter continuously increases with the increased ply-orientation till it reaches $\theta \approx( \pm 45)_{s}$ and decreases thereafter with the further increased ply-angles irrespective of loading conditions. This behavior is almost similar to that of the horizontal elliptical cutout with higher in the values of buckling parameters. It is also observed from both horizontal and vertical elliptical cutout panels that the panel with pure bending and inverse-sinusoidal load shows highest buckling resistance and the panel with uniform edge load shows least buckling resistance irrespective of ply-orientations. 


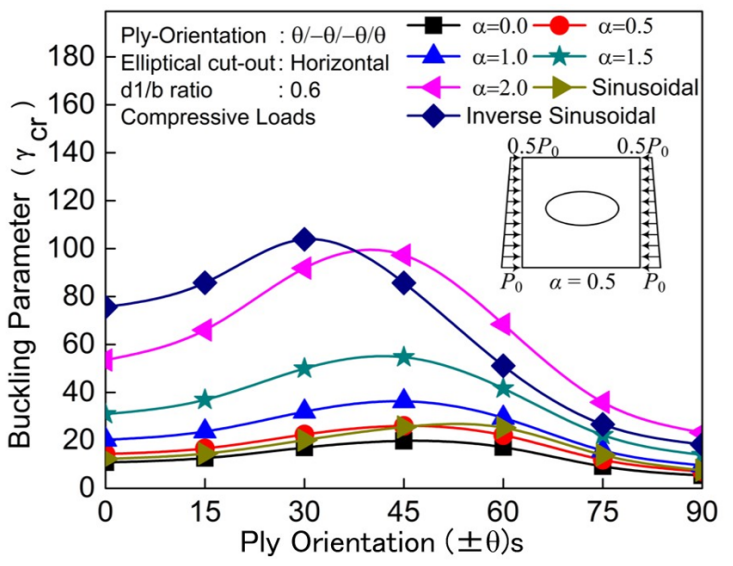

(a) Buckling parameter of an elliptical horizontal cutout panel under different ply-orientations

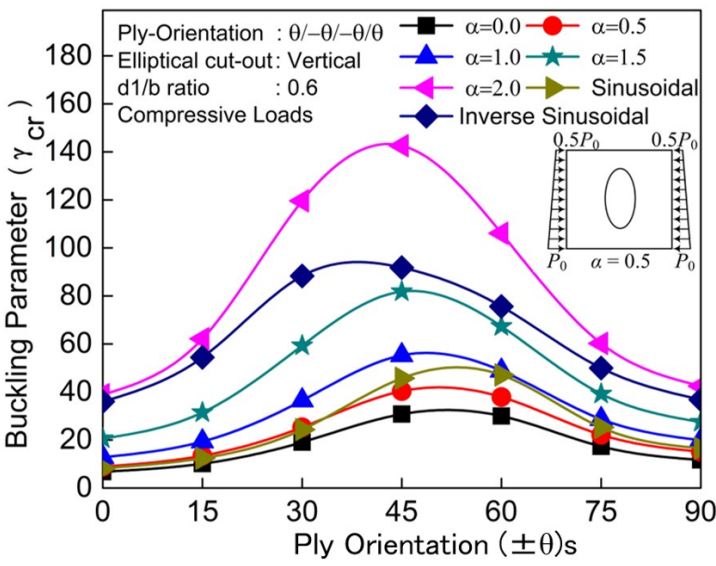

(b) Buckling parameter of an elliptical vertical cutout panel under different ply-orientations

Figure 10 Variation of $\gamma_{\mathrm{cr}}$ with ply-orientation for a panel with $\mathrm{d} 1 / \mathrm{b}=0.6$ under compressive edge loads

\subsubsection{Effect of non-uniform tensile edge loads on different ply-oriented panels}

The effect of non-uniform tensile edge loads on the tensile buckling behavior of horizontal and vertical elliptical cutouts have been studied for different ply-orientations and the results are shown in Figure $11(\mathrm{a})$ and 11 (b) respectively. It is observed from Figure 11(a) that the buckling parameter initially increases with the increase in ply-orientation till it reaches $\theta=( \pm 30)_{s}$ and thereafter it decreases up to $\theta=( \pm 60)_{s}$ and again increases with the further increase in ply-orientation irrespective of loading conditions except for in-plane bending ( $\alpha=1.5$ and 2.0). In the case of in-plane bending, the buckling parameter found to be maximum at $\theta=( \pm 45)_{s}$. It is important to mention that the panel with pure in-plane bending $(\alpha=2.0)$ shows least the buckling resistance, whereas it is highest in the case of compression buckling. The similar behavior with lower in the values of buckling parameter is observed when the panel provided with vertical elliptical cutout, which can be seen in Figure 11(b). It is worthwhile to mention that in the case of tension buckling, horizontal elliptical cutout panel shows highest buckling resistance as compared to that of vertical elliptical cutout panel irrespective of loading conditions. This is reversed in the case of compression buckling wherein the vertical elliptical cutout panel shows highest buckling resistance.

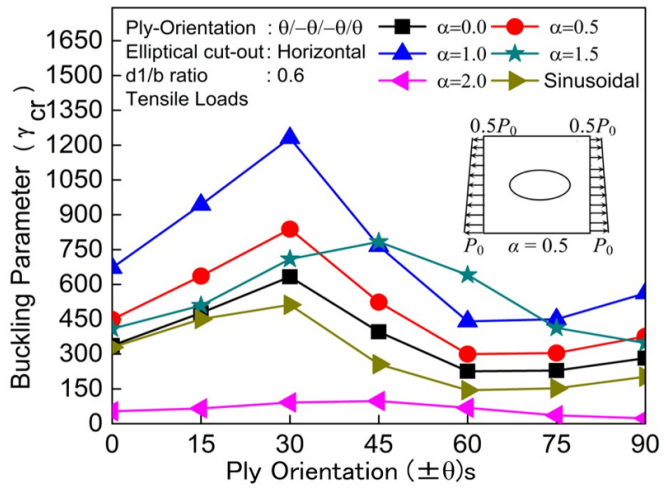

(a) Buckling parameter of an elliptical horizontal cutout panel under different ply-orientations

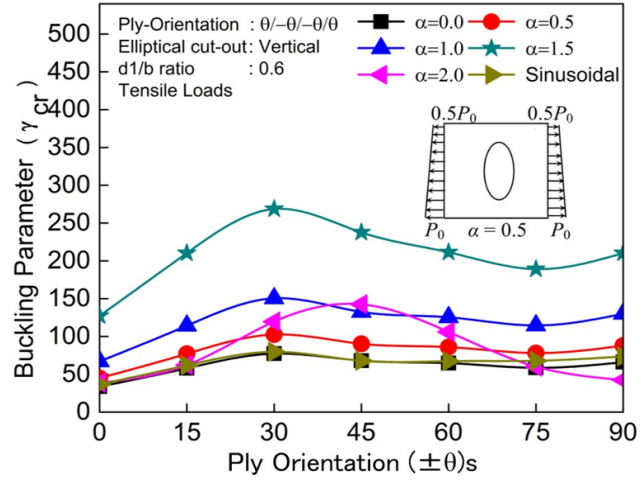

(b) Buckling parameter of an elliptical vertical cutout panel under different ply-orientations

Figure 11 Variation of $\gamma_{\mathrm{cr}}$ with ply-orientation for a panel with $\mathrm{d} 1 / \mathrm{b}=0.6$ under tensile edge loads

\subsubsection{Effect of orientation of elliptical cutouts under different compressive loadings}

The effect of elliptical cutout orientation $(\psi)$ on the buckling characteristics of cross-ply and angle-ply laminated panels has been investigated by considering different non-uniform edge loads and the results are shown in Figure 12(a) and 12 (b) respectively. The cutout size $\mathrm{d} 1 / \mathrm{b}$ is considered as 0.6 and the ratio of elliptical major to minor axis diameter is restricted to 2 . It is observed from the cross-ply laminate scheme as shown in Figure 12(a) that the buckling parameter slightly increases with the increase in cutout orientation $(\psi)$ from $0^{\circ}$ to $90^{\circ}$ irrespective of non-uniform edge loads.

In the case of angle-ply layup scheme as observed in Figure 12(b), the variation in the buckling parameter with the cutout orientation $(\psi)$ is found to be increased significantly with higher buckling parameters as compared to that of 
cross-ply laminate scheme. It is worthwhile to mention that the panel with pure bending $(\alpha=2.0)$ and uniformly distributed load $(\alpha=0.0)$ shows highest and lowest buckling resistance respectively as compared to all other loading conditions for both cross-ply and angle-ply laminate schemes.

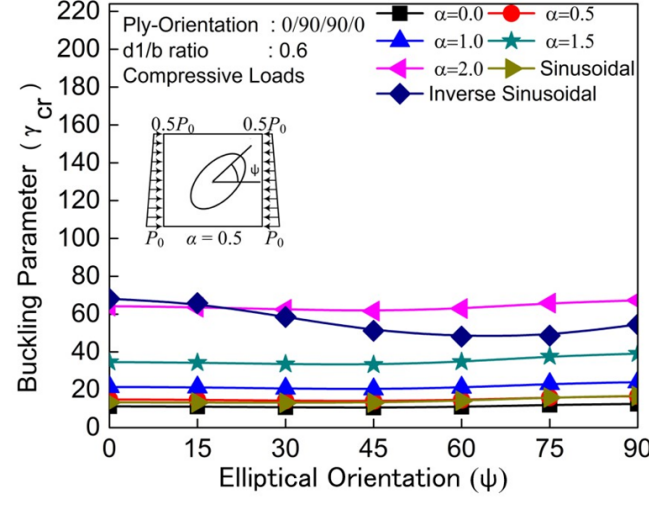

(a) Buckling parameter of a cross-ply panel under different cutout orientations $(\psi)$

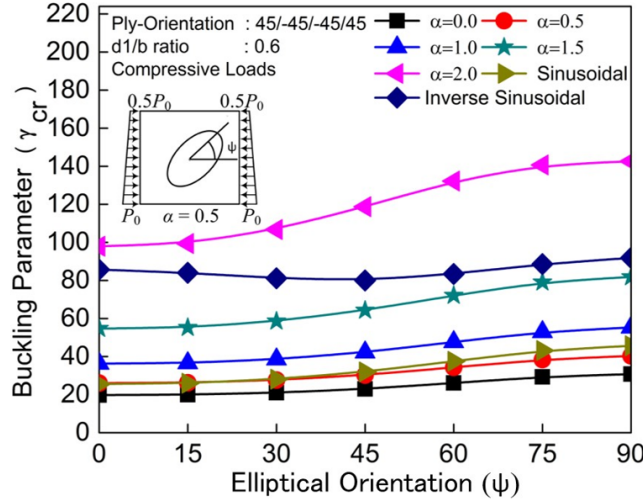

(b) Buckling parameter of an angle-ply panel under different cutout orientations $(\psi)$

Figure 12 Variation of $\gamma_{\mathrm{cr}}$ with cutout orientation $(\psi)$ for a panel under different compressive edge loads

\subsubsection{Effect of orientation of elliptical cutouts under different tensile edge loadings}

The effect of different non-uniform tensile edge loads on the tension buckling characteristics of cross-ply and angleply laminated panels with different elliptical cutout orientations $(\psi)$ has been studied and the results are illustrated in Figure 13(a) and 13(b) respectively. The cutout orientation considered here is varied from $\psi=0^{\circ}$ to $90^{\circ}$. The cutout with $\psi=0^{\circ}$ and $90^{\circ}$ indicates the elliptical cutout placed horizontally and vertically, respectively. It is observed from Figure $13(\mathrm{a})$ and $13(\mathrm{~b})$ that the buckling parameter decreases with the increase in cutout orientation $(\psi)$ and found to be least buckling resistance at $\psi=90^{\circ}$ and maximum at $\psi=0^{\circ}$ irrespective of loading conditions except for pure bending, wherein the buckling parameter increases with the increase in cutout orientation. The increase in buckling parameter in the case of pure bending is almost negligible in the case of cross-ply laminate scheme as compared to that of the angle-ply laminate scheme. It is worthwhile to mention that the panel with angle-ply laminate shows the highest tension buckling resistance as compared to that of cross-ply laminates, irrespective of loading conditions and elliptical orientations.

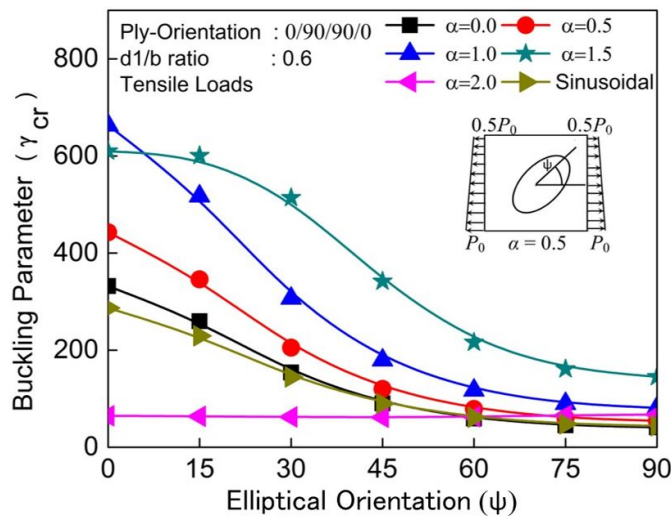

(a) Buckling parameter of a cross-ply panel under different cutout orientations $(\psi)$

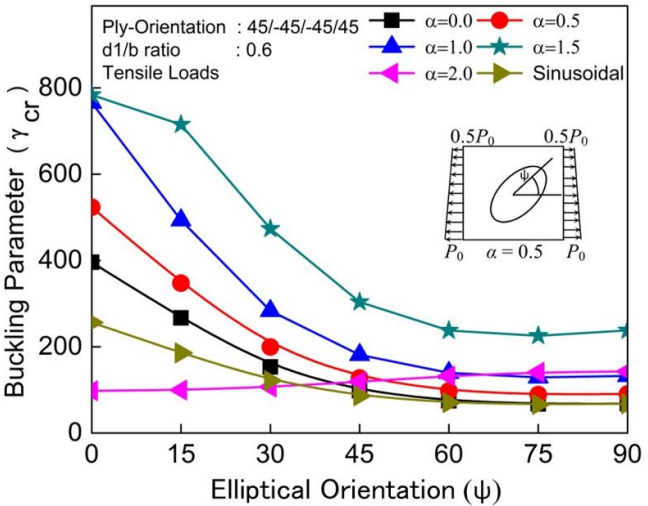

(b) Buckling parameter of an angle-ply panel under different cutout orientations $(\psi)$

Figure 13 Variation of $\gamma_{\mathrm{cr}}$ with cutout orientation $(\psi)$ for a panel under different tensile edge loads

\subsubsection{Effect of elliptical axis ratio under compressive edge loads}

The effect of elliptical axis ratio (i.e., the ratio of major axis by minor axis diameter, $\mathrm{d} 1 / \mathrm{d} 2$ ) on the buckling behavior of angle-ply laminated panel has been investigated by considering horizontal and vertical elliptical cutout and the results are shown in Figure 14(a) and $14(\mathrm{~b})$ respectively. The ratio of $\mathrm{d} 1 / \mathrm{d} 2=1.0$ indicate circular cutout and $\mathrm{d} 1 / \mathrm{d} 2>1.0$ indicate elliptical cutout. It is noticed from Figure 14(a) that for any given non-uniform edge load, the variation in the buckling parameter with elliptical axis ratio $(\mathrm{d} 1 / \mathrm{d} 2)$ is almost negligible in the case of the horizontally placed elliptical cutout. In 
the case of the vertically placed elliptical cutout, the buckling parameter significantly increases with the increase in elliptical axis ratio $(\mathrm{d} 1 / \mathrm{d} 2)$ irrespective of loading conditions and found highest buckling resistance when $\mathrm{d} 1 / \mathrm{d} 2=6.0$ and least resistance when $\mathrm{d} 1 / \mathrm{d} 2=1.0$ as seen in Figure 14(b). It also observed from both the cases that for a given $\mathrm{d} 1 / \mathrm{d} 2$, the panel with vertical elliptical cutout shows highest buckling resistance as compared to that of horizontal elliptical cutout irrespective of loading conditions. It is worthwhile to mention in both the cases that the panel with pure in-plane bending shows highest buckling resistance. In contrast, it is least in the case of uniformly distributed edge load irrespective of elliptical axis ratio (d1/d2).

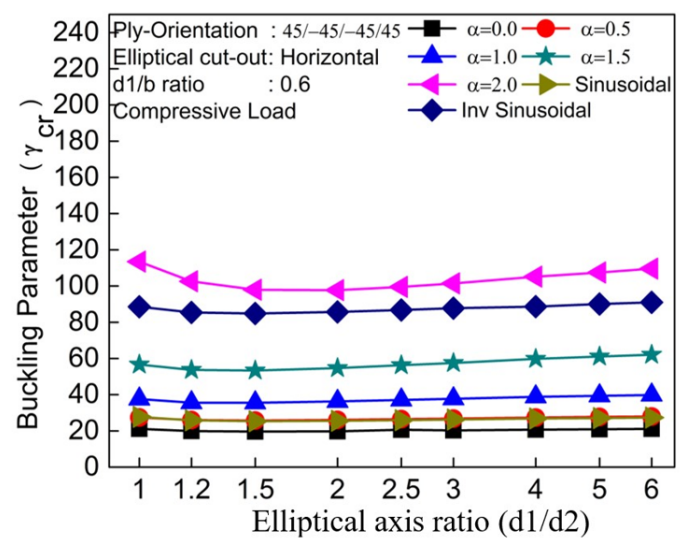

(a) Buckling parameter of an angle-ply panel with horizontal elliptical axis ratio $(d 1 / d 2)$

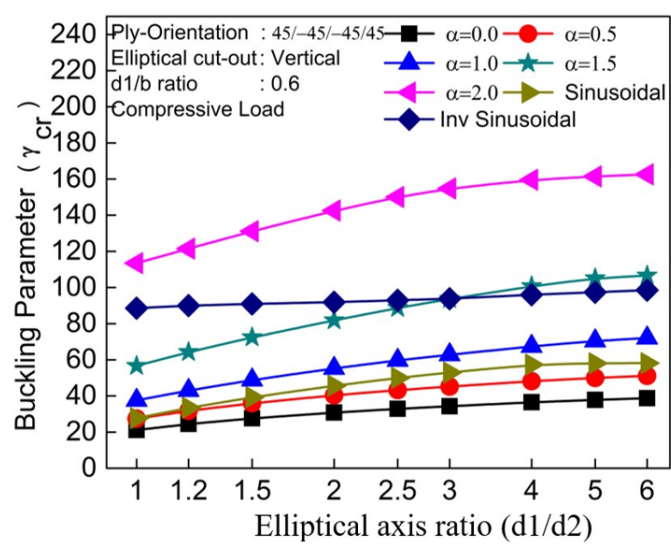

(b) Buckling parameter of an angle-ply panel with vertical elliptical axis ratio $(d 1 / d 2)$

Figure 14 Variation of $y c r$ with elliptical axis ratio under non-uniform compressive edge loads

\subsubsection{Effect of thickness and boundary conditions}

The effect of thickness ratio (b/t) on the buckling characteristics of simply supported (SSSS) and clamped (CCCC) angle-ply square panel with horizontal and vertical elliptical cutouts have been studied for various non-uniform edge loads and the numerical results are tabulated in Table 4 and Table 5 respectively. For all the cases, $d 1 / d 2$ ratio is restricted as 2.0 and $d 1 / b$ is taken as 0.6 . It is observed from Table 4 and Table 5 that in the thin plate configuration (b/t $=100)$, clamped panel shows significantly higher buckling resistance as compared to that of simply supported panel irrespective of loading conditions and this significance in buckling resistance keeps on reducing and found almost equal for both simply supported and clamped conditions in thick plate configuration $(b / t=10)$. This phenomenon may be attributed to the fact that the boundary condition plays a significant role in flexural stiffness of panel only in thin plate configuration. It is also observed from Tables 4 and 5, that in thin plate configuration, the panel with vertical elliptical cutout shows higher buckling resistance as compared to that of horizontal elliptical cutout irrespective of loading and boundary conditions. This is not true in thick plate configuration, wherein the panel with horizontal elliptical cutout shows higher buckling resistance as compared to that of vertical elliptical cutout panels for all loading and boundary conditions.

Tables4 Variation of buckling parameter for different thickness angle-ply square panel with horizontal elliptical cutout under different non-uniform edge loads

\begin{tabular}{ccccccccc}
\hline $\mathbf{d} \mathbf{1} / \mathbf{b}=\mathbf{0 . 6}$ & \multicolumn{2}{c}{$\mathbf{b} / \mathbf{t}=\mathbf{1 0 0}$} & \multicolumn{2}{c}{$\mathbf{b} / \mathbf{t}=\mathbf{5 0}$} & \multicolumn{2}{c}{$\mathbf{b} / \mathbf{t}=\mathbf{2 0}$} & \multicolumn{2}{c}{$\mathbf{b} / \mathbf{t}=\mathbf{1 0}$} \\
\hline Loading pattern & SSSS & CCCC & SSSS & CCCC & SSSS & CCCC & SSSS & CCCC \\
$\alpha=0.0$ & 19.78 & 38.09 & 19.01 & 34.02 & 15.98 & 21.69 & 8.98 & 9.02 \\
$\alpha=0.5$ & 26.06 & 47.63 & 24.98 & 42.37 & 20.56 & 26.9 & 11.22 & 11.53 \\
$\alpha=1.0$ & 36.63 & 62.79 & 34.45 & 55.77 & 27.28 & 35.21 & 14.74 & 15.58 \\
$\alpha=1.5$ & 54.73 & 91.81 & 51.35 & 81.24 & 39.41 & 50.46 & 17.92 & 18.08 \\
$\alpha=2.0$ & 97.92 & 166.93 & 90.95 & 145.52 & 66.58 & 72.85 & 19.36 & 19.45 \\
Sinusoidal & 25.59 & 47.39 & 24.54 & 42.3 & 20.42 & 26.79 & 10.26 & 10.26 \\
Inverse-sinusoidal & 85.7 & 187.83 & 82.79 & 166.66 & 69.77 & 86.19 & 22.98 & 23.08 \\
\hline
\end{tabular}


Table 5 Variations of buckling parameter for different thickness angle-ply squares panel with vertical elliptical cutout under different non-uniform edges loads

\begin{tabular}{|c|c|c|c|c|c|c|c|c|}
\hline \multirow{2}{*}{$\begin{array}{c}\mathrm{d} 1 / \mathrm{b}=0.6 \\
\text { Loading pattern }\end{array}$} & \multicolumn{2}{|c|}{$b / t=100$} & \multicolumn{2}{|c|}{$b / t=50$} & \multicolumn{2}{|c|}{$b / t=20$} & \multicolumn{2}{|c|}{$b / t=10$} \\
\hline & SSSS & $\operatorname{cccc}$ & SSSS & $\operatorname{cccc}$ & SSSS & cccc & SSSS & cccC \\
\hline$\alpha=0.0$ & 30.8 & 51.23 & 28.25 & 40.3 & 13.64 & 13.65 & 3.47 & 3.47 \\
\hline$\alpha=0.5$ & 40.37 & 64.15 & 36.68 & 50.19 & 17.11 & 17.12 & 4.36 & 4.36 \\
\hline$\alpha=1.0$ & 55.27 & 84.62 & 49.28 & 66.07 & 22.94 & 22.95 & 5.86 & 5.86 \\
\hline$\alpha=1.5$ & 81.85 & 123.73 & 72.11 & 96.27 & 34.62 & 34.63 & 8.89 & 8.89 \\
\hline$\alpha=2.0$ & 142.57 & 225.17 & 126.15 & 173.65 & 64.91 & 66.0 & 17.24 & 17.24 \\
\hline Sinusoidal & 45.69 & 73.27 & 41.41 & 57.31 & 18.85 & 18.86 & 4.82 & 4.82 \\
\hline Inverse-sinusoidal & 91.83 & 166.42 & 86.36 & 133.42 & 49.27 & 49.34 & 12.6 & 12.6 \\
\hline
\end{tabular}

\section{CONCLUSION}

The results from the compression and tension buckling behavior of composite laminated panel with different oriented elliptical cutouts under non-uniform in-plane edge loads are summarized as follows:

- The panel with vertical elliptical cutout shows highest buckling resistance as compared to that of horizontal elliptical cutout only in the case of compressive loading conditions, whereas it is reversed in the case of tensile loading conditions.

- Angle-ply laminates are preferable over cross-ply laminates irrespective of elliptical cutout orientations, cutout sizes and loading conditions.

- For a particular elliptical cutout ratio, the orientation of elliptical cutout plays a significant role in buckling resistance only in the case of angle-ply laminates, whereas it is insignificant in the cross-ply laminate scheme. The buckling resistance of the panel increases with the increase in the orientation of cutout from $0^{\circ}$ to $90^{\circ}$ and it is found to be decreased in the case of tension buckling.

- Circular cutouts are more susceptible to buckle at lower values as compared to that of elliptical cutouts.

- As the thickness of the panel increase, the buckling load parameter becomes independent of boundary conditions for all considered layup schemes, cutout size and loading conditions.

- For a particular elliptical cutout ratio, the buckling resistance of the panel increases with the increase in elliptical axis ratio $(\mathrm{d} 1 / \mathrm{d} 2)$ only when the cutout is placed vertically, whereas it is insignificant when the cutout is placed horizontally irrespective of loading.

- The panel with vertical elliptical cutout is preferred only in thin plate configuration; in contrast, the panel with the horizontal elliptical cutout is preferred in thick plate configuration irrespective of loading conditions.

- The panel under the action of pure in-plane bending $(\alpha=2.0)$ and inverse-sinusoidal load shows highest buckling resistance whereas the panel under uniformly distributed load $(\alpha=0.0)$ shows least buckling resistance for any cutout parameter.

Author's Contribution: Conceptualization, Subash Chandra K S, T Rajanna and K Venkata Rao; Methodology, T Rajanna; Investigation, Subash Chandra K S; Writing - original draft, Subash Chandra K S; Writing - review \& editing, T Rajanna and K Venkata Rao; Supervision, T Rajanna and K Venkata Rao.

Editor: Marco L. Bittencourt 


\section{References}

Abolghasemi, S., Eipakchi, H. and Shariati, M. (2019). An analytical solution for buckling of plates with circular cutout subjected to non-uniform in-plane loading, Arch Appl Mech 89: 2519-2543. https://doi.org/10.1007/s00419-019-01592-3.

Aydin Komur, M. and Sonmez, M. (2008). Elastic buckling of rectangular plates under linearly varying in-plane normal load with a circular cutout, Mechanics Research Communications, 35(6): 361-371. https://doi.org/10.1016/j.mechrescom.2008.01.005.

Aydin Komur, M., Sen, F., Ataş, A., \& Arslan, N. (2010). Buckling analysis of laminated composite plates with an elliptical/circular cutout using FEM. Advances in Engineering Software, 41(2), 161-164. doi:10.1016/j.advengsoft.2009.09.005

Bathe, K.J. (1996). Finite element procedures, Prentice Hall, Englewood Cliffs.

Baba, B.O. and Baltaci, A. (2007). Buckling characteristics of symmetrically and antisymmetrically laminated composite plates with central cutout, Applied Composite Materials, 14(4): 265-276. https://doi.org/10.1007/s10443-007-9045-z.

Bourada, M., Bouadi, A., Bousahla, AA, Senouci, A., Bourada, F., Tounsi, A., \& Mahmoud, SR (2019). Buckling behavior of rectangular plates under uniaxial and biaxial compression, Structural Engineering and Mechanics, 70 (1): 113-123. https://doi.org/10.12989/sem.2019.70.1.113.

Butalia, T.S., Kant, T. and Dixit, V.D. (1990). Performance of heterosis element for bending of skew rhombic plates, Computers \& Structures, 34(1): 23-49. https://doi.org/10.1016/0045-7949(90)90298-G.

Chandra K.S.S., Rao K.V., Rajanna T. (2021). Effect of Varying In-Plane Loads and Cutout Size on Buckling Behavior of Laminated Panels. In: Kalamkar V., Monkova K. (eds) Advances in Mechanical Engineering. Lecture Notes in Mechanical Engineering. Springer, Singapore. https://doi.org/10.1007/978-981-15-3639-7_80

Chandra K.S.S., Rajanna T., Rao K.V. (2020a). Effect of sinusoidal and inverse sinusoidal In-plane loads on buckling and vibration characteristics of FRP panels with cutouts, Materials Today: Proceedings. https://doi.org/10.1016/j.matpr.2020.09.231.

Chandra K.S.S., Rajanna T., Rao K.V. (2020b). Effect of position of partial load on buckling and vibration characteristics of composite panels with circular cutouts, Materials Today: Proceedings. https://doi.org/10.1016/j.matpr.2020.09.229.

Deolasi, P.J., Datta, P.K. and Prabhakar, D.L. (1995). Buckling and vibration of rectangular plates subjected to partial edge loading (compression or tension)., Journal of Structural Engineering, 22(3): 135-144.

Ghannadpour, S.A.M., Najafi, A. and Mohammadi, B. (2006). On the buckling behavior of cross-ply laminated composite plates due to circular/elliptical cutouts, Composite structures, 75(1): 3-6. https://doi.org/10.1016/j.compstruct.2006.04.071.

Hughes, T.J.R. and Cohen, M. (1978). The heterosis finite element for plate bending, Computers \& Structures, 9(5): $445-450$. https://doi.org/10.1016/0045-7949(78)90041-X.

Jain, P. and Kumar, A. (2004). Postbuckling response of square laminates with a central circular/elliptical cutout, Composite Structures, 65(2): 179-185. https://doi.org/10.1016/j.compstruct.2003.10.014.

Khedmati, Mohammad Reza, \& Edalat, Pedram. (2010). A numerical investigation into the effects of parabolic curvature on the buckling strength and behaviour of stiffened plates under in-plane compression. Latin American Journal of Solids and Structures, 7(3), 249-264. https://doi.org/10.1590/S1679-78252010000300002.

Kumar, D. and Singh, S.B. (2010). Effects of boundary conditions on buckling and postbuckling responses of composite laminate with various shaped cutouts, Composite Structures, 92(3): 769-779.

https://doi.org/10.1016/j.compstruct.2009.08.049.

Lal, R. and Saini, R. (2013). Buckling and vibration of non-homogeneous rectangular plates subjected to linearly varying inplane force, Shock and Vibration, 20(5): 879-894. https://doi.org/10.1155/2013/579813.

Leissa, A.W. and Ayoub, E.F. (1988). Vibration and buckling of a simply supported rectangular plate subjected to a pair of inplane concentrated forces, Journal of Sound and Vibration, 127(1): 155-171. https://doi.org/10.1016/0022-460X(88)90356-2.

Mirzaei, Saeed, Azhari, Mojtaba, \& Bondarabady, Hossein Ali Rahimi. (2015). On the use of finite strip method for buckling analysis of moderately thick plate by refined plate theory and using new types of functions. Latin American Journal of Solids and Structures, 12(3), 561-582. https://doi.org/10.1590/1679-78251280. 
Muc, A. (2018). Peculiarities in the material design of buckling resistance for tensioned laminated composite panels with elliptical cut-outs. Materials, 11(6), 1019.https://doi.org/10.3390/ma11061019.

Muc, A., \& Romanowicz, P. (2017). Effect of notch on static and fatigue performance of multilayered composite structures under tensile loads. Composite Structures, 178: 27-36. https://doi.org/10.1016/j.compstruct.2017.07.004.

Muc, A., Barski, M., Chwał, M., Romanowicz, P., Stawiarski, A. (2018a). Fatigue damage growth monitoring for composite structures with holes. Composite Structures, 189: 117-126. https://doi.org/10.1016/j.compstruct.2018.01.065.

Muc, A., Chwał, M., \& Barski, M. (2018b). Remarks on experimental and theoretical investigations of buckling loads for laminated plated and shell structures. Composite Structures, 203, 861-874. https://doi.org/10.1016/j.compstruct.2018.07.094

Narayana, A.L., Rao, K. and Kumar, R.V. (2014). Buckling analysis of rectangular composite plates with rectangular cutout subjected to linearly varying in-plane loading using fem, Sadhana, 39(3): 583-596. https://doi.org/10.1007/s12046-014-0250-9.

Choudhary, P.K. and Jana, P. (2018). Position optimization of circular/elliptical cutout within an orthotropic rectangular plate for maximum buckling load, Steel and Composite Structures, 29(1): 39-51. https://doi.org/10.12989/scs.2018.29.1.039.

Rajanna, T., Banerjee, Sauvik, Desai, Yogesh M., \& Prabhakara, D. L. (2016a). Effects of Partial Edge Loading and Fibre Configuration on Vibration and Buckling Characteristics of Stiffened Composite Plates. Latin American Journal of Solids and Structures, 13(5), 854-879. https://doi.org/10.1590/1679-78252239.

Rajanna, T., Sauvik, Banerjee., Yogesh, M, Desai., Prabhakara, D.L. (2016b). Vibration and buckling analyses of laminated panels with and without cutouts under compressive and tensile edge loads, Steel and Composite Structures, 21(1): 37-55. https://doi.org/10.12989/scs.2016.21.1.037.

Rajanna, T., Sauvik, Banerjee., Yogesh, M, Desai., Prabhakara, D.L. (2017). Effect of boundary conditions and non-uniform edge loads on buckling characteristics of laminated composite panels with and without cutout, International Journal for Computational Methods in Engineering Science and Mechanics, 18(1): 64-76. https://doi.org/10.1080/15502287.2016.1276350.

Rajanna, T., Banerjee, S., Desai, Y. M., \& Prabhakara, D. L. (2018). Effect of reinforced cutouts and ply-orientations on buckling behavior of composite panels subjected to non-uniform edge loads. International Journal of Structural Stability and Dynamics, 18(04), 1850058. https://doi.org/10.1142/S021945541850058X.

Reddy, J.N. (1996). Mechanics of laminated composite plates, CRC press, New York.

Reddy, J.N. and Phan, N.D. (1985). Stability and vibration of isotropic, orthotropic and laminated plates according to a higherorder shear deformation theory, Journal of Sound and Vibration, 98(2): 157-170. https://doi.org/10.1016/0022$460 \times(85) 90383-9$

Savin, G.N. (1962). The stress distribution in a thin shell with an arbitrary hole, Problems in Cominuum Mechanics, SIAM: Philadelphia,PA, USA, p. 382.

Sayyad, A. S., \& Ghugal, Y. M. (2014). Buckling and free vibration analysis of orthotropic plates by using exponential shear deformation theory. Latin American Journal of Solids and Structures, 11(8), 1298-1314. https://doi.org/10.1590/S167978252014000800001.

Sayyad, Atteshamuddin S., Shinde, Bharti M., \& Ghugal, Yuwaraj M. (2016). Bending, Vibration and Buckling of Laminated Composite Plates Using a Simple Four Variable Plate Theory. Latin American Journal of Solids and Structures, 13(3), 516-535. https://doi.org/10.1590/1679-78252241.

Shimizu, S. (2007). Tension buckling of plate having a hole, Thin-walled structures, 45(10): 827-833. https://doi.org/10.1016/j.tws.2007.08.033.

Singh, S. K., \& Chakrabarti, A. (2012). Buckling analysis of laminated composite plates using an efficient CO FE model. Latin American Journal of Solids and Structures, 9(3), 1-13. https://doi.org/10.1590/S1679-78252012000300003

Tang, Y. and Wang, X. (2011). Buckling of symmetrically laminated rectangular plates under parabolic edge compressions, International Journal of Mechanical Sciences, 53(2): 91-97. https://doi.org/10.1016/j.ijmecsci.2010.11.005.

Zhong, H. and Gu, C. (2007). Buckling of symmetrical cross-ply composite rectangular plates under a linearly varying in-plane load, Composite Structures, 80(1): 42-48. https://doi.org/10.1016/j.compstruct.2006.02.030. 